\title{
Extrahepatic Bile Duct Neuroendocrine Neoplasm
}

National Cancer Institute

\section{Source}

National Cancer Institute. Extrahepatic Bile Duct Neuroendocrine Neoplasm. NCI

Thesaurus. Code C96954.

A neoplasm with neuroendocrine differentiation that arises from the extrahepatic bile ducts. It includes well differentiated neuroendocrine tumors (low and intermediate grade) and poorly differentiated neuroendocrine carcinomas (high grade). 